
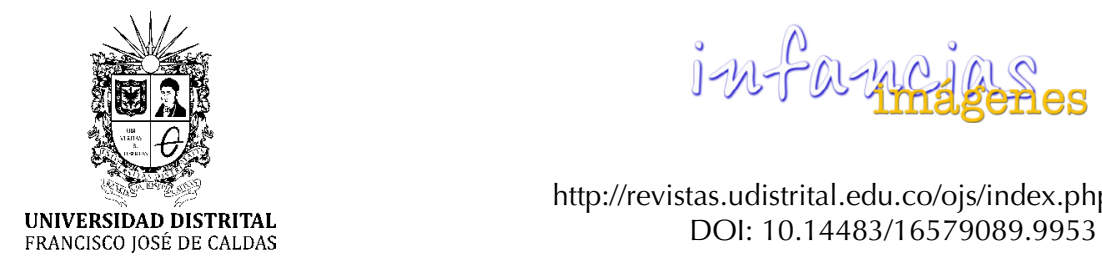

http://revistas.udistrital.edu.co/ojs/index.php/infancias DOI: $10.14483 / 16579089.9953$

PERFILES Y PERSPECTIVAS

\title{
De infancia invisible a infancia-s visibles
}

\author{
From Invisible Childhood to Visible Childhood-s
}

Martha Ligia Calle Pinto ${ }^{1}$

Para citar este artículo: Calle, M. L. (2017). De infancia invisible a infancia-s visibles. Infancias Imágenes, 16(2), 330-334.

\section{Resumen}

Este texto nace como parte de un ejercicio de reflexión en torno a la condición infantil desarrollado a partir del proceso de formación en el seminario sobre Infancias, juventudes y educación, y producto de la tesis Las contravenciones y las infracciones escolares: Un análisis del hurto y robo como expresiones de la violencia escolar, desarrollada en el Doctorado Interinstitucional de Educación de la Universidad Distrital Francisco José de Caldas. Busca mostrar algunos elementos para poder visibilizar la infancia, teniendo en cuenta la experiencia educativa a partir de tres conceptos: el primero referido a la escuela como institución que garantiza los derechos, siendo el fundamental la educación; el segundo, con referencia a la visibilización del cuerpo; y el tercero, relacionado con la necesidad de una contracultura frente a modelos que impiden la formación de la subjetividad y promueven el consumo y las ideologías hegemónicas.

Palabras clave: infancia; escuela; educación; visibilización del cuerpo; contracultura; subjetividad.
Recibido: 28-diciembre-2016/Aprobado: 25-septiembre-2017

\begin{abstract}
This text emerges as part of an exercise of reflection on child condition developed from the training process in the seminar "Childhood, Youth and Education," and product of the doctoral thesis: Violations and school infractions: A analysis of theft and robbery as expressions of school violence of the Interinstitutional Doctorate of Education of the University District Francisco José de Caldas. It seeks to show some elements to be able to visualize childhood, considering the educational experience, from three concepts; The first one referred to the school as an institution that guarantees rights, education being the fundamental. The second, with reference to the visibility of the body; and the third related to the need for a counterculture against models that impede the formation of subjectivity and promote consumption and hegemonic ideologies.
\end{abstract}

Keywords: childhood; school; education; visibilization of the body; counterculture; subjectivity.

\footnotetext{
1 Licenciada en Psicología y Pedagogía, Magíster en Desarrollo Educativo y Social, candidata a Doctora en Educación del Doctorado Interinstitucional de Educación de la Universidad Francisco José de Caldas. Docente orientadora de la Secretaría de Educación, docente de la Universidad Pedagógica Nacional.
} 


\section{Introducción}

La condición infantil contemporánea plantea una diferenciación frente a lo que se ha comprendido como infancia. Por una parte, asociada a una etapa de desarrollo o edad cronológica, y por otra, a una construcción cultural, social, política, estética y económica. La infancia era un momento de crecimiento caracterizado por la dependencia, el cuidado higiénico, la subordinación al adulto, la normatización y regulación de la mente y del cuerpo. Todo con el objeto de: "educar al niño para no castigar al hombre". Es decir, la infancia era una preparación para la vida adulta. Y allí radicaba su valor. Así la infancia se hace invisible, pues el niño solo existe como un proyecto de adulto o ciudadano. En contraposición, se plantea la visibilización de las infancia-s en plural, comprendiendo que esta construcción histórica y cultural no se constituye en un molde y obedece más a procesos sociales y subjetivos que a etapas de desarrollo teóricas. El niño o niña es un sujeto que existe en el presente. Piensa, vive, actúa y ya es un ciudadano. Se relaciona con el mundo fáctico y a través de la experiencia, construye y reconstruye su mundo de la vida ${ }^{2}$, en una formación dialéctica entre la intersubjetividad y el mundo social.

Las infancia-s, según Amador, pueden comprenderse como:

[...] el conjunto de circunstancias sociales, subjetivas, epistémicas y políticas en las que se produce el tránsito de la infancia en singular (noción prototípica del proyecto de la modernidad) a las infancias (categoría analítica que da cuenta de la pluralidad de los mundos de vida de los niños y niñas en el tiempo presente). (2012, p. 74)

\footnotetext{
2 Para este propósito Husserl reconoce en primera instancia la existencia de un mundo factico y objetivo que tenemos ante nuestros ojos y que se puede percibir a través de los sentidos y la intuición; esto es a través de la realidad concreta, de las cosas, los sujetos que nos rodean, aquellos que podemos ver y sentir, pero que también podemos intuir, expresión que Husserl utiliza para referirse a la posibilidad de evocación que tenemos sobre lo que conocemos y recordamos. A partir de este mundo real es que cada uno de nosotros da constitución al mundo de la vida, que nace de la subjetividad y en el que nada es definitivo, sino que es permanentemente cambiante y reconfigurado en las nuevas experiencias con los otros que nos rodean y que comienzan a hacer parte de él. Es decir, también es intersubjetivo, desde él aprehendemos la vida, la cultura, los valores, etc.
}

Pero para poder visibilizar las infancia-s, y teniendo en cuenta la experiencia educativa, es necesario empoderar tres conceptos. El primero referido a la escuela como institución que garantiza los derechos, siendo el fundamental la educación. El segundo, con referencia a la visibilización del cuerpo. Y el tercero, se relaciona con la necesidad de una contracultura frente a modelos que impiden la formación de la subjetividad y promueven el consumo y las ideologías hegemónicas.

\section{La escuela: un espacio para la recons- trucción del mundo de la vida infantil}

El mundo de la vida es un conglomerado sociocultural integrado por opciones de valor, experiencias subjetivas y sedimentos históricos; es el mundo donde se nace y se muere, donde se hereda una tradición cultural, donde se comunica un lenguaje, donde se vive intersubjetivamente. Es el mundo de la cotidianidad en cuyo horizonte nos encuadramos para orientarnos y es, a la vez tejido de relaciones sociales; es el mundo del trabajo, de la familia, de los usos y costumbre. (Herrera, 2002, pp. 64-65, citado en Guevara, 2014, p. 83)

Así, se puede decir que la escuela es también ese lugar de transmutación del mundo de la vida, en el que los niños, niñas y jóvenes comparten experiencias no solo en la formación disciplinar de las matemáticas, las ciencias y el lenguaje sino, además, y según mi criterio como lo más importante, en la vida social misma.

Desde hace más de dos décadas la escuela, en su intento por configurar un nuevo ciudadano, viene desarrollando múltiples propuestas para garantizar a los niños su condición de sujetos de derecho. Entre ellas encontramos la formación en educación sexual, en democracia y más reciente aún en ciudadanía. Sin embargo, estos propósitos mundiales, regionales y locales no generan un impacto en los niños, niñas y jóvenes escolares. La educación no es realmente el camino para la transformación de las realidades de los sujetos estudiantes, como lo expresa Cajíao:

La "consignación" de los jóvenes a la escuela se fundamentó en la transferencia de un conocimiento 
del "mundo adulto" al "mundo de los jóvenes", aunque muchas veces no respondiera a las verdaderas necesidades e intereses de los adolescentes.

Así la posesión o carencia del saber se constituyó en un elemento de dominación-subordinación que el desarrollo social ha legitimado. (Cajíao, 1995, p. 135)

Así pues, la institución escuela debe replantearse. No podemos desconocer que ella es una institución viva a través de los niños, jóvenes y maestros, sus relaciones, modos de ser y relacionarse con el afuera. Ya no es posible concebir la formación democrática como un mero ejercicio de simulación de la vida real; o la educación sexual con un cúmulo de información sin formación; o la educación ciudadana como un relato de "competencias" que permiten a niños y jóvenes llamarse "ciudadanos".

El lugar de la educación ya no es exclusivo de la escuela, esto convoca al sistema educativo a una reflexión en torno a la cultura y nuestra historicidad, un volver en nosotros mismos para reconocernos en el ejercicio de configurar una nueva cultura en la que se reconozca la pluralidad, y se propicien espacios de reconocimiento de las diversidades que constituyen el país. El mundo de la vida infantil es entonces un campo de complejidades históricas, culturales y sociales, que el niño, niña y joven trae consigo. Lo determina, pero no lo condena. Así, el papel de la educación es definitivo para crear nuevos sentidos del mundo y de sí mismo. Las infancias requieren de espacios para ser repensadas y reconstruidas, como lugares de derecho y de reconocimiento.

\section{La visibilización del cuerpo de las infancias}

En la escuela el cuerpo se invisibiliza. Los conocimientos se centran en la razón y la corporalidad no es tenida en cuenta. El niño, niña o joven es una cabeza cargada por un cuerpo. Al desaparecer, pierde su sentido de existencia. Al no ver, sentir y explorar el cuerpo se pierde el sujeto, del cual solo se requieren sus respuestas observables. Por tanto, el hecho de confinar al cuerpo en una dinámica de mero razonamiento se le desplaza de herramienta existencial a neto instrumento receptivo. Zandra
Pedraza, antropóloga de la Universidad de los Andes, escribe al respecto:

Tal obstáculo ha surgido porque se postula al sujeto ante todo como un ente racional, vaciado de sus circunstancias somáticas. Por efecto de este acercamiento, en la escuela el conocimiento aparece a menudo como producto de una forma incorpórea de ejercitar la razón, que acontece como externalidad del sujeto corpóreo en un ambiente desencarnado en el que habita, solo, el logos. (2010, p. 48)

Lo que evidencia la importancia de problematizar el cuerpo como una circunstancia existencial, que de manera inseparable con la razón está inmersa en el aprendizaje y que al situarlo en un espacio específico, en este caso la escuela, aparece como facilitador de otros conocimientos, aparte de lo meramente académico, como por ejemplo: imaginarios del mundo de la vida, modos de concebir el propio cuerpo y el del otro, maneras de socializar ideas en pro de la construcción de lenguajes propios y comunes, etc.

Al pensarse el cuerpo en la escuela y en la infancia, se sugiere una transgresión del término tradicional que abandone la percepción única desde el ámbito cotidiano e instrumental, para concientizar al sujeto estudiante de las posibilidades que posee en su particularidad y que cada uno descubra de manera personal su potencial en la creación, en la acción y en el pensamiento. Del mismo modo, se propone problematizar la dimensión-cuerpo en todos los aspectos de la vida y no solo en el ámbito escolar.

David Le Breton (2002), en su texto Antropología del cuerpo y modernidad, expone cómo la corporeidad se instituye como un fenómeno social a través del cual se representa y se percibe el mundo. "El cuerpo parece algo evidente, pero nada es, más inaprehensible como él. Nunca es un dato indiscutible, sino el efecto de una construcción social y cultural" (p. 14).

Y, además, refiere en su libro La sociología del cuerpo la relación corpórea con el entorno y la aproximación que se da entre la existencia individual y la colectiva para construir conocimiento. Así, se entiende que en el cuerpo se alojan aprendizajes 
traspasados por la educación, la familia, la sociedad, etc., que estructuran los comportamientos de las personas. Así describe la importancia de la socialización en las infancias desde lo corporal: "Este proceso de socialización de la experiencia corporal es una constante de la condición social del hombre que, sin embargo, tiene sus momentos más fuertes en ciertos momentos de su existencia, especialmente en la infancia y en la adolescencia" (Le Breton, 2002, p. 8).

Así, visibilizando los cuerpos en su marco subjetivo, se puede contribuir a dibujar las infancias. El cuerpo es una de las más importantes construcciones del ser humano, delimita su existencia. Por esto es necesario que la escuela lo tome como objeto de aprendizaje, enseñanza y conocimiento. No solo como instrumento, medio u objeto de entrenamiento físico. El cuerpo es el sujeto mismo.

\section{Contracultura para formar las subjeti- vidades de las infancias}

La cultura y el momento histórico actual hacen que los niños y niñas estén rodeados de ideologías que los seducen, particularmente por los medios de comunicación. Contrario a lo que puede pensarse, estos medios no son neutrales. Están cargados de ideologías y contenidos que mantienen las posturas tradicionales, coloniales, hegemónicas y patriarcales. Así, Disney, Discovery, Cartoon Network, entre otros, brindan los conceptos, socialmente aceptados, de sujeto, belleza, política, masculinidad, feminidad, justicia. Giroux plantea que:

cuestionar lo que enseña Disney, forma parte de una indagación mucho más amplia sobre qué necesitan saber los familiares, los niños, los educadores y otros trabajadores culturales para poder criticar y poner en tela de juicio, en caso necesario las fuerzas institucionales y culturales que tienen un impacto directo en la vida pública. (Giroux, 2001, p. 124)

Amador (2002) expone a las tecnologías como las nuevas formas de producción de conocimiento que se encuentran inmersas en el mundo del niño contemporáneo. En esta categoría se aprecian claramente los símbolos e imágenes que se han acentuado en la mente del niño para representarse a sí mismo en el mundo, como es la imagen del súper héroe o la princesa, que a su vez se convierten en modos particulares de habitar el mundo.

Los medios masivos se han convertido en una referencia clara de quién se es, o cómo llegar a ser de determinada manera. Por esto, la escuela que quiera visibilizar las infancias debe apostar a la construcción de una contracultura que rompa con las ideas impuestas por las ideologías tradicionales. Donde la infancia se ha llevado al plano de las industrias y los niños y sus padres son consumidores en potencia. La fantasía, la inocencia, la imaginación, la ternura, entre otras, son bienes de consumo más que características de la infancia.

Según Giroux, los medios de comunicación y la cultura que promueven tienen una relación directa con la economía

[...] En una época en que las corporaciones poseen un poder desmesurado para transformar la cultura infantil con un empeño fundamentalmente comercial, utilizando sus diversas tecnologías culturales como máquinas docentes para mercantilizar y homogeneizar implacablemente todos los aspectos de la vida cotidiana, y suponiendo así una amenaza potencial a las verdaderas libertades asociadas a una democracia sustantiva. (Giroux, 2001, p.124)

Generar desde el campo de la educación un giro y verdadera mirada sobre la infancia en todo su esplendor, al niño, niña y joven como un verdadero sujeto con mucho que decir sobre la sociedad y con mucho que aportar, es todavía un reto en la escuela, en donde la mirada del maestro parece aún no haberse podido descentrar de la perspectiva adultocéntrica que promueve la invisibilización de las infancias, desde el no reconocimiento de ese otro completo que es el niño.

El reto es ahora la transformación de las prácticas escolares en donde nuevas miradas sobre el mundo, la subjetividad y la cultura, pueden ser el camino.

\section{Referencias}

Amador, J. C. (2002). Infancias, subjetividades y cibercultura: noopolítica y experiencia de sí. Revista Científica, 15(1), 12-29. 
. (2012). Condición infantil contemporánea: hacia una epistemología de las infancias. Pedagogía y Saberes, 37, 73-87.

Cajíao, F. (1995). Proyecto Atlántida. Estudio sobre el adolescente escolar en Colombia. Tomos I-IV. Bogotá: Fundación FES.

Giroux, H. A. (2001). Cultura, política y práctica educativa. Barcelona: Biblioteca de Aula.
Guevara, A. C. (2014). Lo poético y la vida: fenomenología de la creación estética. Bogotá: San Pablo. Le Breton, D. (2002). Antropología del cuerpo y modernidad. Buenos Aires: Nueva Visión.

Pedraza, Z. (2010). Saber, cuerpo y uso de los sentidos y escuela: la educación somática. Calle 14: Revista de Investigación en el Campo del Arte, 4(5), 44-57. 